\title{
Cobalamin deficiency resulting in a rare haematological disorder: a
} case report

\author{
Thomas M Chapuis*, Bernard Favrat and Patrick Bodenmann
} \author{
Switzerland \\ Email: Thomas M Chapuis* - Thomas.Chapuis@chuv.ch; Bernard Favrat - Bernard.Favrat@chuv.ch; \\ Patrick Bodenmann - Patrick.Bodenmann@hospvd.ch \\ * Corresponding author
}

Address: Department of Ambulatory Medicine and Community Healthcare, University of Lausanne, Rue du Bugnon 44, CH-1011 Lausanne,

Published: 20 October 2009

Journal of Medical Case Reports 2009, 3:80 doi:10.1186/1752-1947-3-80
Received: 9 January 2009

Accepted: 20 October 2009

This article is available from: http://www.jmedicalcasereports.com/content/3/l/80

(C) 2009 Chapuis et al; licensee BioMed Central Ltd.

This is an Open Access article distributed under the terms of the Creative Commons Attribution License (http://creativecommons.org/licenses/by/2.0), which permits unrestricted use, distribution, and reproduction in any medium, provided the original work is properly cited.

\begin{abstract}
Introduction: We present the case of a patient with a cobalamin deficiency resulting in pancytopaenia, emphasizing the importance to define, diagnose and treat cobalamin deficiency.

Case presentation: A 52-year-old man from the Democratic Republic of Congo presented to the emergency department with shortness of breath and a sore tongue. Physical examination was unremarkable. His haemoglobin was low and the peripheral blood smear revealed pancytopaenia with a thrombotic microangiopathy. The findings were low cobalamin and folate levels, and high homocysteine and methylmalonate levels. Pernicious anaemia with chronic atrophic gastritis was confirmed by gastric biopsy and positive antiparietal cell and anti-intrinsic factor antibodies. Cobalamin with added folate was given. Six months later, the patient was asymptomatic.
\end{abstract}

Conclusion: Cobalamin deficiency should always be ruled out in a patient with pancytopaenia. Our case report highlights a life-threatening cobalamin deficiency completely reversible after treatment.

\section{Introduction}

Pernicious anaemia is a common cause of cobalamin deficiency, as discussed by Biermer in 1872. Whipple, Minot and Murphy developed a treatment with a liver extract in the late 1920s, suggesting an association between an extrinsic factor found in the liver and an intrinsic factor in the gastric juice. Folkers $e t$ al. isolated the extrinsic factor, that is, cobalamin, in the late 1940s. In the 1950s, Hodgkin $e$ al. used X-ray crystallography to reveal the structure of cobalamin. Nevertheless, there is still no gold standard for diagnosis, and nor are there clear guidelines for the treatment of cobalamin deficiency $[1,2]$.

A population survey in the United States revealed that $1.9 \%$ of people older than 60 years of age have undiag- nosed pernicious anaemia. The introduction of folate fortification in the United States has left some of the population at risk for a masked cobalamin deficiency [3].

\section{Case presentation}

A 52-year-old man from the Democratic Republic of Congo presented to the emergency department after 14 days of shortness of breath, general weakness, weight loss and a sore tongue. He had no cough, chest pain or fever, and there was nothing significant in his medical and family history. He did not smoke nor drink alcohol. On examination, he appeared uncomfortable, anicteric and afebrile with a respiratory rate of 28 per minute, regular pulse of 70 beats per minute and blood pressure of 111/ $76 \mathrm{mmHg}$. A cardiovascular examination showed normal 
heart sounds and his lungs were clear on auscultation. The patient's tongue was unremarkable, as were the abdominal and neurologic examinations.

A chest X-ray and a full blood count were then ordered. The patient's chest X-ray was normal. His full blood count examination showed pancytopaenia. His hematocrit was $21 \%$ with a mean corpuscular volume of $107 \mathrm{fl}$ and an absolute reticulocyte count of $31,000 / \mathrm{mm}^{3}$. His white blood cell count was $3600 / \mathrm{mm}^{3}$ with $27 \%$ neutrophils, $63 \%$ lymphocytes and $96,000 / \mathrm{mm}^{3}$ platelets. A peripheral blood smear (Figure 1) revealed anisocytosis and hypersegmented neutrophils. Other findings were low levels of cobalamin (52 pmol/l; normal range: 133-675), folate (4.2 nmol/l; normal value: $>6.8)$, and haptoglobin $(<0.1$ $\mathrm{g} / \mathrm{l}$; normal range: 0.3-2), and high levels of lactate dehydrogenase (LDH) (4604 U/l; normal range: 135-225), homocysteine (Hcys) (101 $\mu \mathrm{mol} / \mathrm{l}$; normal range: $5-15)$, and methylmalonate (MMA) $(1.12 \mu \mathrm{mol} / \mathrm{l}$; normal value: $<0.28)$. The level of the patient's creatinine $(83 \mu \mathrm{mol} / \mathrm{l}$; normal range: $62-106)$ and potassium $(4.4 \mathrm{mmol} / \mathrm{l}$; normal range: 3.6-4.4) were normal, as were the other findings. A gastroscopy showed oedematous gastric mucosa and a biopsy showed atrophic gastritis (Figure 2). Antiparietal cell and anti-intrinsic factor antibodies were positive.

The patient was given two units of packed red cells, which improved his respiratory symptoms. Cobalamin $(1000 \mu \mathrm{g}$ intramuscularly) was given daily for 7 days, then weekly for 4 weeks, and then prescribed at a maintenance dose of $1000 \mu \mathrm{g}$ once a month for life [4]. Daily folate of $5 \mathrm{mg}$ orally was also given for 3 months. The patient was not admitted and follow-up was arranged in our ambulatory setting.

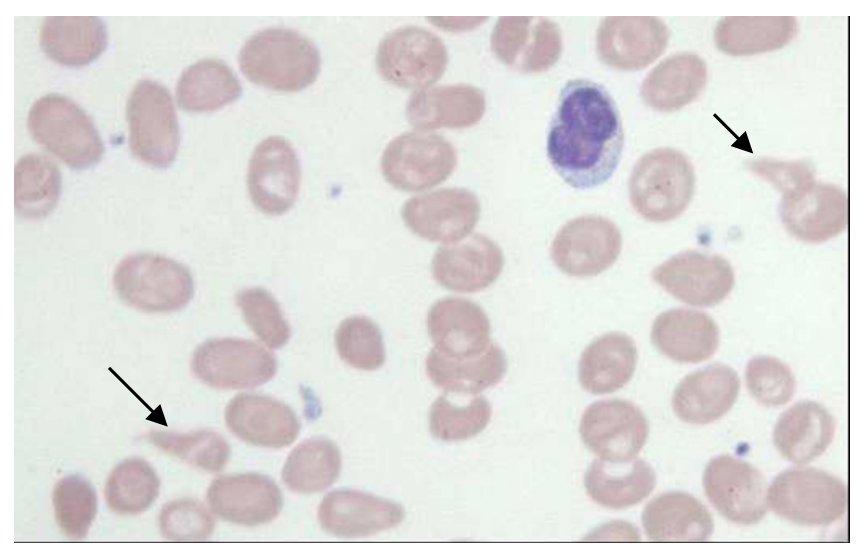

Figure I

Peripheral blood smear (May-Grünwald Giemsa stain), 500x. Macro-ovalocytes. Schistocytes (arrows).

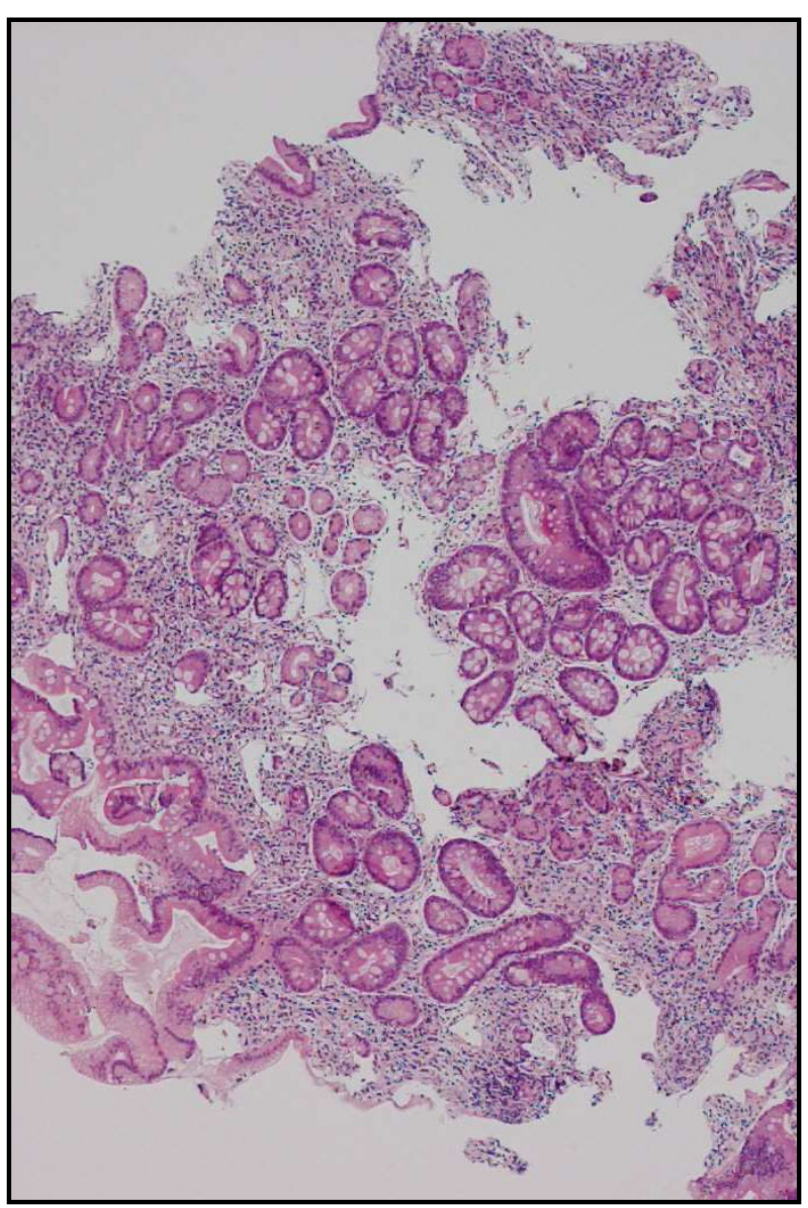

\section{Figure 2}

Gastric (body) biopsy (haematoxylin and eosin), 40x. Intestinal metaplasia with goblets cells. The lamina propria is filled with lymphocytes.

Nine days after introduction of therapy, correction of his deficiencies led to marked reticulocytosis $(200,000 /$ $\mathrm{mm}^{3}$ ). Six months later, the patient was asymptomatic and the peripheral blood smear was normal. His levels of cobalamin $(505 \mathrm{pmol} / \mathrm{l})$, folate $(9.6 \mathrm{nmol} / \mathrm{l} ;>5.3)$, MMA $(0.26 \mu \mathrm{mol} / \mathrm{l} ;<0.28)$, and Hcys $(9.8 \mu \mathrm{mol} / \mathrm{l} ; 5-15)$ were also normal.

\section{Discussion}

Cobalamin deficiency was our leading diagnosis; other causes of pancytopenia including dysthyroidism, HIV, Epstein-Barr virus, cytomegalovirus, herpes simplex virus, hepatitis $B$ virus and hepatitis $C$ virus infection were ruled out afterwards. Myeloproliferative disorders were less likely, and for this reason, a bone marrow aspiration was not performed. Pulmonary tuberculosis was not suggested given the absence of history and a normal chest X-ray. The 


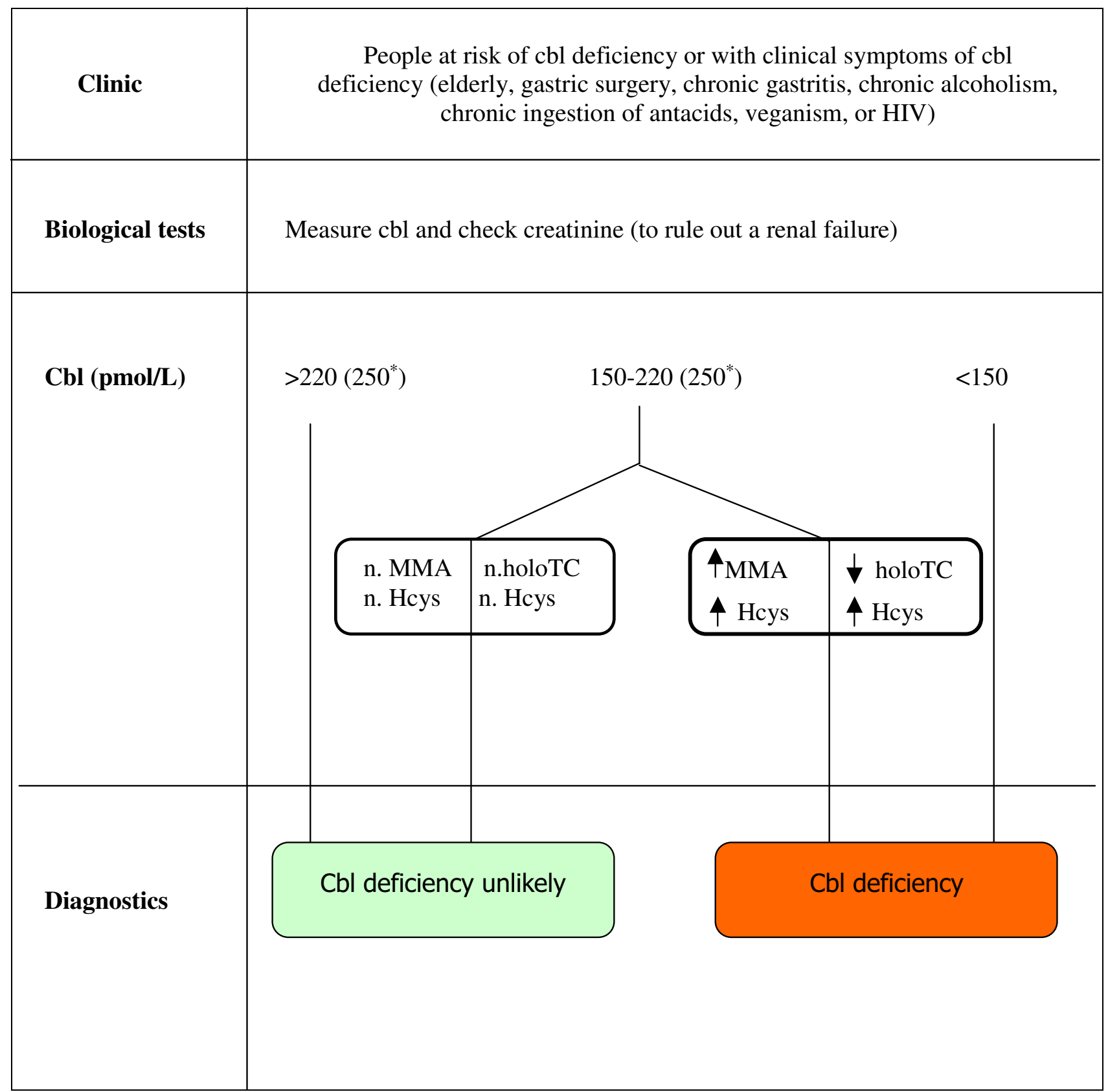

\section{Figure 3}

Diagnostic and therapeutic approach for cobalamin deficiency [2,4]. Cbl (cobalamin), MMA (methylmalonate), Hcys (homocysteine), holoTC (holotranscobalaminll), PA (pernicious anaemia), n. (normal) *No clear consensus among authors to identify the grey zone (I50-250 pmol/L).

dramatic response to therapy precluded any necessity for further investigations.

Most patients with cobalamin deficiency exhibit signs of peripheral nervous system or spinal cord involvement [5]. Our patient developed a non-neurologic manifestation - a sore tongue that was proven reversible after treatment. Severe life-threatening haematologic findings such as pancytopaenia, thrombotic microangiopathy and haemolytic anaemia (high LDH, low haptoglobin, schistocytes and thrombopaenia) due to cobalamin deficiency were observed in our patient. These findings are rare and were 
observed in less than $5 \%$ of the patient population in a French study of severe haematological conditions resulting from cobalamin deficiency [5]. There are also case reports involving severe cobalamin deficiency that mimicked leukaemia or thrombotic microangiopathy [6-8].

The prevalence of cobalamin deficiency is notable, especially among older individuals (14\%) [9]. General population studies show a prevalence of cobalamin deficiency of around $20 \%$ in Western countries [4]. Until recently, it was believed that pernicious anaemia involved mainly Caucasians, but previous studies provide evidence that pernicious anaemia is as common in Africans also [10].

The most common causes of cobalamin deficiency are food-cobalamin malabsorption and pernicious anaemia, mainly among older people. Other causes include dietary deficiency, malabsorption and hereditary metabolic disease [5]. Patients at risk for cobalamin deficiency include those who have had gastric surgery or a history of chronic gastritis, chronic alcoholism, chronic ingestion of antacids, veganism or HIV [4].

Diagnosing cobalamin deficiency is straightforward when the deficiency is profound. Nevertheless, diagnosing a slight deficiency is more difficult in older patients and in patients with neurological symptoms who present a borderline cobalamin level. Classically, the diagnosis is based on a low cobalamin level, but elevated MMA and Hcys levels seem more sensitive and more specific [11]. Renal failure may also increase MMA and Hcys levels and high Hcys level may also reveal a folate deficiency [11].

Solomon evaluated patients for cobalamin deficiency using the standard metabolic markers MMA and Hcys in a retrospective study of the records of patients in an ambulatory setting over a 10-year period [12]. The levels of the three metabolic markers were measured before any treatment was given. Cobalamin, MMA, Hcys levels showed a wide variability over time, and taken individually or in combination did not predict or rule out a haematological or neurological response to cobalamin therapy [12].

There are also new methods available to diagnose cobalamin deficiency. In plasma, total plasma cobalamin is bound to two proteins, haptocorrin and transcobalamin. Normally, $80 \%$ of cobalamin is on plasma haptocorrin and forms a holohaptocorrin. About $20 \%$ of cobalamin is combined with transcobalamin II to form the biologically active fraction holotranscobalamin II (holoTC), which is available for cell use. HoloTC levels seem to be an early indicator of cobalamin deficiency [13]. Several studies showed that holoTC might be a promising first-line test or used in combination with a metabolic marker (MMA or
Hcys) for diagnosing cobalamin deficiency $[2,13]$. In patients at risk or with clinical symptoms, we suggest a comprehensive care approach (Figure 3) $[2,4]$.

Anti-intrinsic factors are more specific than antiparietal cell antibodies and are found in the serum of almost $40 \%$ of patients [14]. Both factors were positive in our patient. A gastric biopsy showed a marked lymphocyte infiltrate in the lamina propria, and the mucosa revealed intestinal metaplasia with goblet cells (Figure 2). The standard treatment of cobalamin deficiency is intramuscular, but oral supplementation has shown an efficacy equal to injection for pernicious anaemia and other cobalamin deficiencies [15]. Life-long cobalamin substitution is necessary in pernicious anaemia [4].

\section{Conclusion}

We present an unusual case of cobalamin deficiency resulting in severe pancytopaenia with thrombotic microangiopathy that was completely reversible after cobalamin substitution. Primary care physicians must be aware of patients at risk for cobalamin deficiencies irrespective of the ethnic origin of the patient. No single algorithm fits every patient, and there is no clear consensus on how to diagnose and treat cobalamin deficiency. Consequently, the diagnosis should rely on clinical epidemiology, clinical symptoms and biochemical markers.

\section{Abbreviations}

Hcys: homocysteine; LDH: lactate dehydrogenase; MMA: methylmalonate.

\section{Consent}

Written informed consent was obtained from the patient for publication of this case report and any accompanying images. A copy of the written consent is available for review by the Editor-in-Chief of this journal.

\section{Competing interests}

The authors declare that they have no competing interests.

\section{Authors' contributions}

TMC carried out the literature review and wrote the case report and is the patient's caregiver. He also obtained the written consent of the patient. BF had a significant role in data analysis and in revising the manuscript. PB had a significant role in data analysis and in the final revision of the manuscript. All authors read and approved the final manuscript.

\section{Acknowledgements}

We thank Dr Igor Letovanec from the Department of Pathology, Dr Anne Cairoli from the Division of Haematology, Dr Carlos Madrid from the Division of Stomatology and Paul Vaucher Msc. 


\section{References}

I. Carmel R, Green R, Rosenblatt DS, Watkins D: Update on Cobalamin, Folate, and Homocysteine. Hematology 2003:62-8I.

2. Schneede J: Prerequisites for establishing general recommendations for diagnosis and treatment of vitamin BI2 deficiency and cost-utility evaluation of these guidelines. Scand J Clin Lab Invest 2003, 63:369-376.

3. Carmel R: Prevalence of undiagnosed pernicious anemia in the elderly. Arch Intern Med 1996, I 56: I097-I I00.

4. Andrès E, Loukili N, Noel E, Kaltenbach G, Ben Abdelgheni M, Perrin A, Noblet-Dick M, Maloisel F, Schlienger J, Blicklé J: Vitamin B I 2 (cobalamin) deficiency in elderly patients. CMAJ 2004, | 7 1:25I-259.

5. Andrès E, Affenberger S, Zimmer J, Vinzios S, Grosu D, Pistol G, Maloisel F, Weitten T, Kaltenbach G, Blicklé J: Current hematological findings in cobalamin deficiency. A study of $20 \mathrm{I}$ consecutive patients with documented cobalamin deficiency. Clin Lab Haematol 2006, 28:50-56.

6. Dokal I, Cox T, Galton D: Vitamin B $/ 2$ and folate deficiency presenting as leukaemia. BMJ 1990, 300:1263-1264.

7. Halfdanarson T, Walker J, Litzow M, Curtis H: Severe vitamin B $\mathbf{2}$ deficiency resulting in pancytopenia, splenomegaly and leukoerythroblastosis. Eur J Haematol 2008, 80(5):448-45I.

8. Garderet L, Maury E, Lagrange M, Najman A, Offenstadt, Guidet B: Schizocytosis in pernicious anemia mimicking thrombotic thrombocytopenic purpura. Am J Med 2003, I I 4:423-425.

9. Pennypacker L, Allen R, Kelly JP, Matthews LM, Grigsby J, Kaye K, Lindenbaum K, Stabler SP: High prevalence of cobalamin deficiency in elderly outpatients. J Am Geriatr Soc 1992, 40(I 2): I I 97- I 204.

10. Carmel R: Ethnic and racial factors in cobalamin metabolism and its disorders. Semin Hematol 1999, 36(I):88-100.

11. Snow C: Laboratory diagnosis of vitamin $\mathrm{B} / 2$ and folate deficiency: a guide for the primary care physician. Arch Intern Med 1999, 1 159:1289-1298.

12. Solomon LR: Cobalamin-responsive disorders in the ambulatory care setting: unreliability of cobalamin, methylmalonic acid, and homocysteine testing. Blood 2005, 105(3):978-985

13. Hvas Am, Nexo E: Holotranscobalamin-a first choice assay for diagnosing early vitamin B deficiency? J Intern Med 2005, 257:289-298.

14. Toh B-H, Van Driel IR, Gleeson PA: Pernicious anemia. N Engl J Med 1997, 337: |44|-| 448.

15. Kuzminski AM, Del Giacco EJ, Allen RH, Stabler SP, Lindenbaum J: Effective treatment of cobalamin deficiency with oral cobalamin. Blood 1998, 92:1191-1198.

Publish with Biomed Central and every scientist can read your work free of charge

"BioMed Central will be the most significant development for disseminating the results of biomedical research in our lifetime. "

Sir Paul Nurse, Cancer Research UK

Your research papers will be:

- available free of charge to the entire biomedical community

- peer reviewed and published immediately upon acceptance

- cited in PubMed and archived on PubMed Central

- yours - you keep the copyright

Submit your manuscript here:

http://www.biomedcentral.com/info/publishing_adv.asp
BioMedcentral 